\title{
Quatro décadas (1977-2017) de publicações sobre o consumo de bebidas alcoólicas por estudantes universitários
}

\author{
Carlos Costa \\ Ph.D. in Plant Science McGill University, \\ Docente na IMED Business School - Faculdade IMED (Passo Fundo/RS) \\ $\triangle$ carlos.costa1@gmail.com \\ Kenny Basso \\ Doutor em Administração (UFRGS), Docente na IMED Business School - Faculdade IMED \\ $\triangle$ kenny@imed.edu.br \\ José Carlos Zanelli \\ Psicólogo, Doutor em Educação (UNICAMP), Docente na IMED Business School - Faculdade IMED \\ $\triangle$ jczanelli@terra.com.br \\ Florindo Luiz Castoldi \\ Doutor em Genética e Melhoramento (UFV), Docente na Universidade de Passo Fundo (UPF) \\ $\triangle$ florindocastoldi@gmail.com \\ Elenise Abreu Coelho \\ Psicóloga, Graduada pela Faculdade Meridional (IMED) \\ Mestranda em Psicologia na Universidade Federal de Santa Maria (UFSM) \\ $\triangle$ elenise.ac@gmail.com \\ Ana Paula Pessotto \\ Mestre em Administração IMED Business School - Faculdade IMED \\ Docente na Universidade Regional Integrada do Alto Uruguai e das Missões (Frederico Westphalen/RS) \\ $\triangle$ ana.pessotto87@gmail.com
}

Recebido em 20 de dezembro de 2020
Aceito em 1 de junho de 2021

\begin{abstract}
Resumo:
A passagem da adolescência para a vida adulta e a transição do ensino médio para a universidade são marcadas por significativas mudanças. Nesse período, o aumento nos padrões de consumo de álcool tem sido problema recorrente e observado em âmbito mundial. Este estudo bibliométrico teve como objetivo analisar as ênfases atribuídas pelos autores, em artigos internacionais, aos fatores associados ao consumo de bebidas alcoólicas por estudantes universitários. Foram considerados os artigos indexados em nove bases de dados, no período de 1977 a 2017, a partir do cruzamento dos descritores álcool e estudantes universitários. Para quantificar a co-ocorrência dessas palavras-chave e a associação dos temas pesquisados, foram usados os softwares UCINET e NETDRAW, respectivamente, mantendose apenas as palavras-chave que tiveram duas ou mais relações com outras. Como resultados, verificou-se o aumento gradual de artigos relativos à temática consumo de álcool no contexto universitário. Passando de uma média de 2,5 artigos/ano no período entre 1977 e 2004 para 31 artigos/ano entre 2005 e 2017. Ainda, destacou-se o uso das palavras-chave álcool, estudantes, consumo e uso de álcool. Convém pontuar a co-ocorrência de palavras-chave como binge (uso pesado de álcool por tempo determinado, geralmente por mais de um dia) e drogas.
\end{abstract}

Palavras-chave: Álcool, Educação superior, Binge, Drogas. 


\title{
Four decades (1977-2017) of publications on the alcoholic consumption of university students
}

\begin{abstract}
:
Occurring between high school and university, the transition from adolescence to adulthood is fraught with significant behavioral changes, including rising alcohol consumption. The intensity of research into this worldwide issue was assessed by identifying, through a bibliometric study, the factors most emphasized in published international contributions to research on the consumption of alcoholic beverages by university students. Articles addressing the intersection of alcohol descriptors and university students, published between 1977 and 2017, and indexed in nine databases, were scrutinized for the co-occurrence of relevant keywords and associations between subjects under study using UCINET and NETDRAW software, respectively. In doing so keywords related to two or more other terms cited in the articles (i.e., 191 of 1714) were identified. As a result, there was a gradual increase in articles related to alcohol consumption in the university context. From an average of 2.5 articles / year between 1977 and 2004 to 31 articles / year between 2005 and 2017.This study highlights the use of keywords such as alcohol, students, consumption and alcohol use. The co-occurrence of keywords such as binge (heavy use of alcohol for a fixed time, usually for more than a day) and drugs was also noted.
\end{abstract}

Keywords: Alcohol, Higher school, Education, Binge, Drugs.

\section{Cuatro décadas (1977-2017) publicaciones sobre el consumo de bebidas alcohólicas por estudiantes universitarios}

\section{Resumen:}

La transición de la adolescencia a la edad adulta y la transición de la escuela secundaria a la universidad estan marcadas por cambios significativos. Durante este período, el aumento en los patrones de consumo de alcohol ha sido un problema recurrente y observado en todo el mundo. Este estudio bibliométrico tuvo como objetivo analizar la importància que, segun los autores de diversos estudios internacionales, tienen los factores asociados con el consumo de bebidas alcohólicas por parte de estudiantes universitarios. Consideramos los artículos indexados en nueve bases de datos, de 1977 a 2017, que tienen en cuenta la combinación entre alcohol y estudiantes universitarios. Para cuantificar la concurrencia de estas palabras clave y la asociación de los temas investigados, utilizamos el software UCINET y NETDRAW, respectivamente, manteniendo solo las palabras clave que tenían dos o más relaciones con otros. Como resultado, hubo un aumento gradual en los artículos relacionados con el consumo de alcohol en el contexto universitario. De un promedio de 2.5 artículos / año entre 1977 y 2004 a 31 artículos / año entre 2005 y 2017. Este estudio destaca el uso de palabras clave como alcohol, estudiantes, consumo y consumo de alcohol. También se observó la coincidencia de palabras clave como atracones (uso excesivo de alcohol durante un tiempo fijo, generalmente durante más de un día) y drogas.

Palabras clave: Alcohol, Educación universitária, Atracones, Drogas.

\section{INTRODUÇÃO}

O consumo de álcool pode levar à dependência, caracterizando a doença crônica e multifatorial (genéticos, psicossociais e ambientais), denominada alcoolismo (DE LOOZE et al., 2017; MCCAMBRIDGE, JIM; MCALANEY, JOHN; ROWE, 2011; OMS, 2010). Essa, para o seu desenvolvimento, também depende da quantidade e da frequência de uso do álcool, assim 
como, da condição de saúde geral do indivíduo usuário (DE LOOZE et al., 2017; OMS, 2010). De acordo com a OMS (Organização Mundial de Saúde), é tênue o limite entre o consumo e a dependência, existindo dificuldades para definir o uso moderado ou um nível seguro de ingestão de álcool (OMS, 2010). Mesmo assim, a organização faz distinções entre o beber social, que não significa, necessariamente, beber com moderação; o beber intenso (heavy drinking), que corresponde a mais de duas doses diárias ou a exceder acentuadamente em, por exemplo, uma vez por semana; o beber problemático (problem drinking), que resulta em perda de saúde e ou em problemas sociais. Ainda, refere o consumo compulsivo periódico de bebida (binge drinking), uso proposital e intenso em um período prolongado; e, por fim, o beber pesado episódico (heavy episodic drinking), correspondente a 60 gramas ou mais de álcool em estado puro, em uma única ocasião (OMS, 2010).

O IV Manual Diagnóstico Estatístico de transtornos mentais (DSM-IV), por sua vez, define a dependência do álcool como a repetição de problemas decorrentes do uso da substância, ou seja, quando o consumo é frequente, compulsivo e acompanhado por problemas físicos, psicológicos e sociais. Ainda, conforme a publicação, o consumo de álcool em baixas doses e que considera precauções para a prevenção de acidentes é considerado um consumo de baixo risco. Por outro lado, o abuso de álcool acontece quando o consumo acarreta consequências como acidentes, brigas ou perda de compromissos (APA, 1994).

No Brasil, o II Levantamento Nacional de Álcool e Drogas (LENAD), realizado com maiores de 14 anos de idade no ano de 2012, registra estimativa de 11,7 milhões de pessoas que podem ser enquadradas como dependentes de álcool. Dessas, $62 \%$ são homens e 38\% mulheres, sendo que $22 \%$ revelaram ter experimentado álcool com menos de 15 anos (LARANJEIRA, 2012). Conforme evidenciado pelo autor, esse dado comprovou, em comparação com um levantamento realizado em 2006, crescente precocidade no consumo, tanto entre homens como entre mulheres.

Mais recentemente, a pesquisa realizada pela OMS, divulgada no relatório World Health Statistics de 2017, revelou que o consumo mundial em 2016 foi de 6,4 litros de álcool puro por pessoa com 15 anos ou mais, com variação considerável entre as regiões da OMS (OMS, 2017). Outros resultados do referido relatório dão conta de que mudanças positivas estão sendo observadas, considerando-se o período entre 2007 e 2016. Neste período houve a redução do consumo total em 3,5 litros de álcool puro por pessoa, queda de novos casos de psicose 
alcoólica (de 52,3 para 20,5 por 100.000 habitantes) e diminuição da taxa de mortalidade de homens (OMS, 2017).

Foram várias as iniciativas determinantes para o sucesso de tais números: aumento dos impostos, restrições de venda para bebidas alcoólicas com mais de 15\% de teor alcoólico, definição de um preço mínimo para aquelas cujo teor estivesse acima de $28 \%$ e, ainda, a proibição de propagandas em toda infraestrutura dos meios de transporte público, internet e mídias eletrônicas e impressas, entre outras. Apesar disso, o relatório World Health Statistcs 2017 evidencia a necessidade de se continuar e ampliar tais ações, pois ainda é alta a taxa de pessoas que tornam-se dependentes, especialmente entre a população mais jovem (ROMANO et al., 2007).

Corroboram com esse fenômeno os estudantes universitários. O ingresso no ensino superior pode constituir-se em um período de vulnerabilidade ao consumo abusivo de álcool e outras drogas (SILVA; PETROSKI, 2012; LORANT et al., 2013; RABELO; PRATES; SAMPAIO, 2017). Isso, pois representa um tempo especialmente propício ao convívio e compartilhamento com colegas ou pares, ainda, à autoafirmação simultânea ao distanciamento da família e menor alcance de adultos. Do mesmo modo, é nesse período que os calouros jovens percebem com maior ênfase condições de liberdade e de controle das próprias decisões (MIRI et al., 2011; ROGOWSKA, 2014; RABELO; PRATES; SAMPAIO, 2017).

Somam-se a essas condutas motivadoras, inúmeras variáveis que podem estar associadas aos fatores de riscos em inter-relações com o consumo de álcool por estudantes universitários. Assim, revelam-se como condicionantes que impactam na decisão de beber o contexto escolar imediatamente anterior, contextos públicos ou privados, relato de ter faltado às aulas sem a permissão dos pais e/ou de ter sido vítima de assédio ou bullying. Interferem, também, o grupo de pares, o trabalho, a mídia e a religião. Além disso, o uso de cigarro e outras drogas e a fácil obtenção de bebidas alcoólicas, afetam no hábito de consumo de produtos alcoólicos por universitários (FERREIRA, 2008; BARBOSA FILHO; CAMPOS; LOPES, 2012; JAVIER et al., 2013; MALTA et al., 2014).

Além dos fatores que levam ao consumo, é importante mencionar as implicações ou consequências deste. Assim, destacam-se o baixo desempenho acadêmico, a prática de sexo sem proteção, o envolvimento em brigas e até questões mais severas, como os acidentes automobilísticos e as mortes. Desse modo, o consumo de álcool e os danos decorrentes deste 
ao público universitário colocam em evidência a importância de estudar-se o fenômeno nesse contexto particular (FERREIRA, 2008; JAVIER et al., 2013; ZAPPE; ALVES; DELL'AGLIO, 2018).

Nessa direção, alguns trabalhos relevantes já foram realizados, evidenciando variáveis que impactam no consumo de álcool e drogas em contextos de ensino superior. Dentre esses, menciona-se o conduzido por Faria et al. (2010), que estudaram a relação da atenção dada, a crença na veracidade e a resposta afetiva às propagandas. Ainda, buscaram compreender a relação do uso prévio de cigarro com o consumo de álcool e comportamentos de risco nos estudantes do ensino superior. Pillon et al.(2011), por sua vez, investigaram a espiritualidade e a religião (em que pese a necessária distinção entre esses dois conceitos) em estreita ligação com o uso de álcool entre estudantes da graduação em enfermagem. Esse estudo concluiu que a espiritualidade pode não funcionar como fator protetor para o consumo de álcool, sugerindo que outras variáveis podem estar associadas a este comportamento.

No mesmo sentido dos estudos já citados, pode-se acrescentar o trabalho de Silva et al. (2006), que pesquisaram as relações entre estilo de vida e situação socioeconômica, abarcando, ainda, variáveis como religião, uso de tabaco e drogas ilícitas com o consumo de álcool entre estudantes universitários. Dentre os resultados, os autores constataram que a variável renda familiar mensal se mostrou fortemente relacionada ao uso de álcool e "drogas ilícitas". Também, que alunos que possuíam mais horas livres nos dias úteis, demonstraram maior consumo de tabaco e drogas ilícitas.

Silva et al. (2006) concluíram, em acréscimo, que os índices de consumo de álcool, tabaco e drogas ilícitas eram significativamente maiores em alunos que não possuíam nenhuma religião (89,3\% para álcool, 27,7\% tabaco e 37,7\% drogas ilícitas) do que em relação aos alunos que alimentavam uma crença $(83,1 \%, 20,7 \%$ e $24,6 \%$, respectivamente). Estes resultados diferem do estudo empreendido por Pillon et al. (2011), revelando a falta de consenso entre os estudos sobre o tema e a necessidade de novas pesquisas para esclarecer os preditores desse comportamento entre os estudantes universitários.

Mesmo havendo essas lacunas, as evidências acumuladas pelas pesquisas do fenômeno uso de álcool e a sua ocorrência entre estudantes de nível superior são, obviamente, relevantes para identificar os fatores associados ao consumo, em suas relações multideterminadas e complexas. A identificação e a análise de tais fatores constituem avanço 
significativo para a proposição de intervenções como forma de antecipar e prevenir os danos (RINKER; NEIGHBORS, 2013; SANTOS; PEREIRA; SIQUEIRA, 2013; SALLES et al., 2016; ZAPPE; ALVES; DELL'AGLIO, 2018).

Nesse sentido, os estudos resultantes de análises sistemáticas da literatura buscam reunir os resultados semelhantes nos diversos estudos. Barbosa Fillho, Campos e Lopes (2012), por exemplo, buscaram avaliar a associação de fatores ambientais (religiosidade, condição de trabalho e uso de substâncias entre os amigos e parentes) e psicossociais (como conflitos com pais e sentimentos negativos e de solidão) com o uso de álcool e tabaco entre os adolescentes, em estudo publicados até junho de 2011. Mais recentemente, Zappe, Alves e Dell'Aglio (2018) com o objetivo de analisar o conhecimento sobre comportamentos de risco na adolescência, realizaram uma revisão sistemática de estudos nacionais e internacionais que compreendeu 193 estudos publicados no período de 2002 a 2012.

Sob a perspectiva de identificar as evidências empíricas dos programas de prevenção e redução do consumo de álcool e outras drogas entre os adolescentes, Salles et al. (2016) analisaram 27 estudos, publicados a partir de 2003 e Bedendo, Andrade e Noto (2018) delimitaram suas análises às intervenções realizadas via internet para a redução do consumo de álcool, por meio de 36 estudos. Rabelo, Prates e Sampaio (2017), por sua vez, restringiram seu estudo aos estudantes da área da saúde e avaliaram os hábitos de consumo de álcool nessa população por meio de 17 publicações. Percebe-se, desta forma, que os estudos tem se dedicado pouco a realizar uma análise mais ampla, que objetive investigar a dinâmica da evolução das publicações acerca do assunto e as mudanças que ocorreram ao longo do tempo nas pesquisas sobre o consumo de bebidas alcoólicas entre os estudantes universitários.

Tal demanda justifica a realização do presente estudo, que se deu com o objetivo de analisar estatisticamente as ênfases atribuídas pelos autores às publicações internacionais associadas ao consumo de bebidas alcoólicas por estudantes universitários, no período temporal compreendido entre os anos de 1977 e 2017. Neste sentido, busca-se contribuir com uma análise das pesquisas realizadas nas últimas quatro décadas de forma a auxiliar os pesquisadores na definição de novos estudos sobre a temática. 


\section{METODOLOGIA}

Este estudo caracteriza-se como uma revisão descritiva da literatura (PARÉ et al., 2015), conduzida de acordo com a metodologia Preferred Reporting Items for Systematic Reviews and Meta-Analysis (PRISMA), conforme Moher et al. (2009), por meio da análise sistemática de estudos sobre o consumo do álcool dentre a população universitária, na busca por quantificar os aspectos associados a esse fenômeno.

Para a identificação dos estudos utilizou-se da base de dados indexados no Portal de Periódico da Coordenação de Aperfeiçoamento de Pessoal de Nível Superior (CAPES). Elegeuse esta plataforma de busca, pois se constitui como uma biblioteca virtual que reúne e disponibiliza um acervo de mais de 45 mil títulos com texto completo, 130 bases referenciais, 12 bases dedicadas exclusivamente a patentes, reunindo o melhor da produção científica internacional. Além disso, é uma base gratuita com acesso aberto para as instituições de ensino. O processo de busca se deu por meio dos descritores na língua portuguesa (álcool e estudante universitário) e seus correspondentes em inglês (alcohol consumption, college students, university students) e espanhol (consumo de alcohol en universitários) e o operador booleano and para o refinamento da busca.

Para serem incluídos neste estudo, os artigos deveriam conter abstract, key words, trazer informações sobre a temática do consumo de álcool por universitários e ter acesso disponível, tendo sido produzidos entre 1977 e 2017. Além disso, foram selecionados artigos em que o consumo de álcool, embora não fosse a temática principal, era uma das variáveis analisadas no artigo, ainda, excluídas as publicações como dissertações, teses, resumos e capítulos de livros. Assim, foram selecionadas 440 publicações que atendiam plenamente aos critérios de inclusão, sendo 283 em inglês, 85 em português e 72 em espanhol, que constituíram a base de dados para esta pesquisa, conforme a Figura 1.

As informações colhidas foram tabuladas em planilha Excel, separados por ano, revista, ênfase (temática do artigo) e, ainda, palavras-chave. A partir dessa sistematização, a análise se deu pelo uso da técnica co-word analysis, por meio do software UCINET, que permite investigar os principais temas pesquisados e evidenciar associações entre palavras-chave por meio da construção de várias redes. Para analisar a co-ocorrência de palavras-chave e a associação dos temas foi utilizado o software NETDRAW. Para executar essas análises, 
mantiveram-se apenas as palavras-chave que tiveram duas ou mais relações com outras, perfazendo um total de 191 principais palavras-chave citadas nos artigos.

Figura 1. Diagrama da seleção sistemática dos estudos.

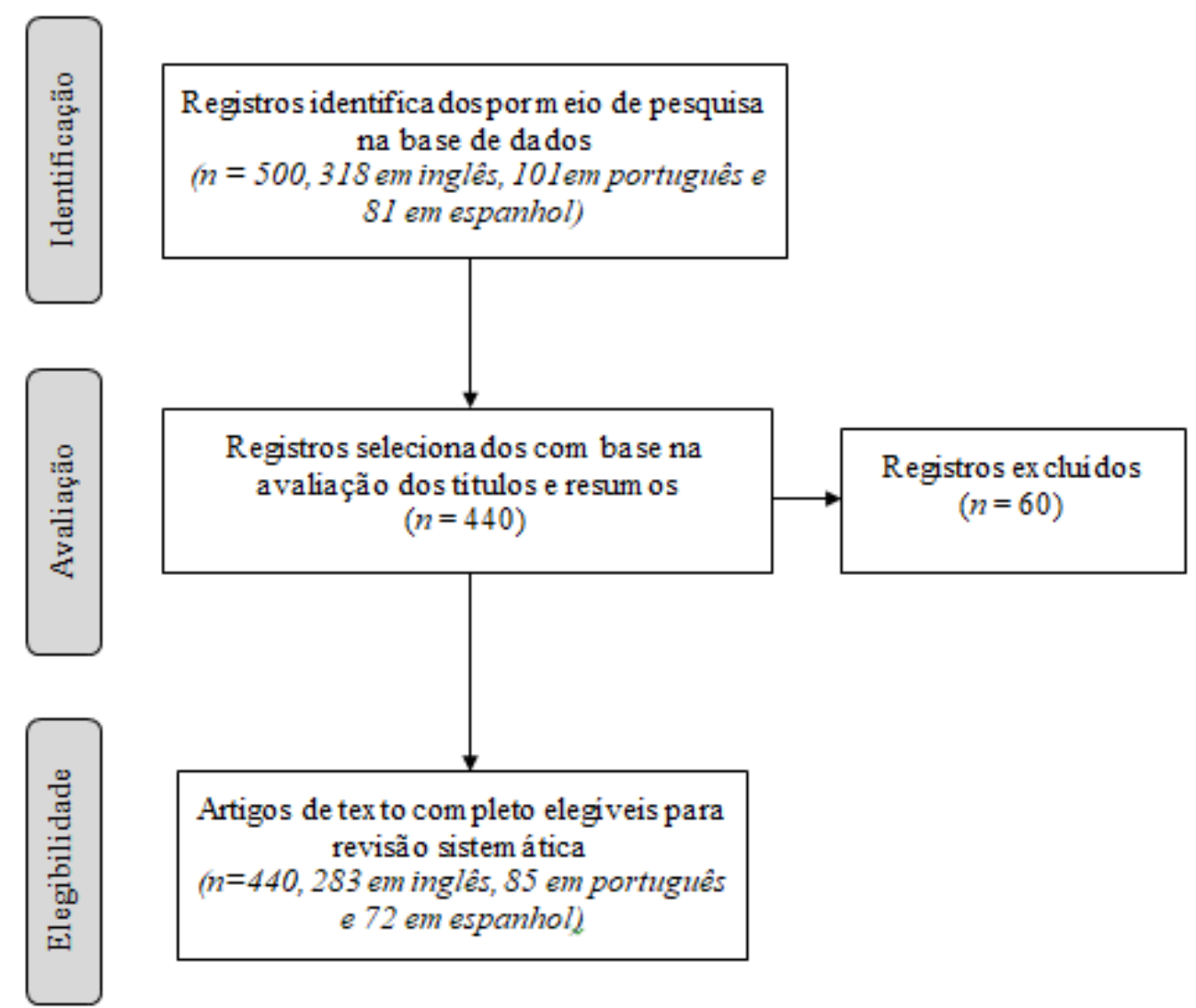

Fonte: Adaptado de MOHER et al., 2009.

Utilizou-se o método de Freeman para medir o grau de proximidade entre os nós, medida que permite verificar como um actor se aproxima do outro na rede (WASSERMAN; FAUST, 1994). Para medir a ligação ou relação entre as principais palavras-chave na rede, foi realizada uma análise de subgrupo com fundamento baseado em blocos. Para a síntese da distribuição das palavras-chave e do grau de centralização na rede, foi escolhida a representação gráfica. Os dados obtidos a partir de tais delineamentos são apresentados e discutidos a seguir. 


\section{RESULTADOS}

Os artigos analisados relativos ao tema consumo de álcool por universitários são distribuídos entre 172 revistas científicas. Destas, cinco concentram 25,6\% dos artigos, a saber, Revista Latino Americana de Enfermagem (7,4 \%), Addictive Behaviors (6,1\%), Journal of American College Health (4,7 \%), Drug and Alcohol Dependence (3,9 \%) e Alcoholism: Clinical and Experimental Research (3,7\%). Em outros 167 periódicos estão distribuídos os 74,4\% dos estudos produzidos no período, representando menos de 1\% em cada revista. Tais números indicam que o tema tem despertado interesse de vários meios de divulgação científica, sem ficar restrito a publicações especializadas, uma vez que algumas revistas têm um único artigo publicado no período de 1977 a 2017. Sobre a distribuição dos artigos no período estudado (1977 a 2017), evidenciou-se uma não uniformidade, tendo havido demarcado interesse no assunto entre os anos 2005 e 2012 (figura 2).

Figura 2. Número de artigos publicados por ano sobre alcoolismo na população universitária.

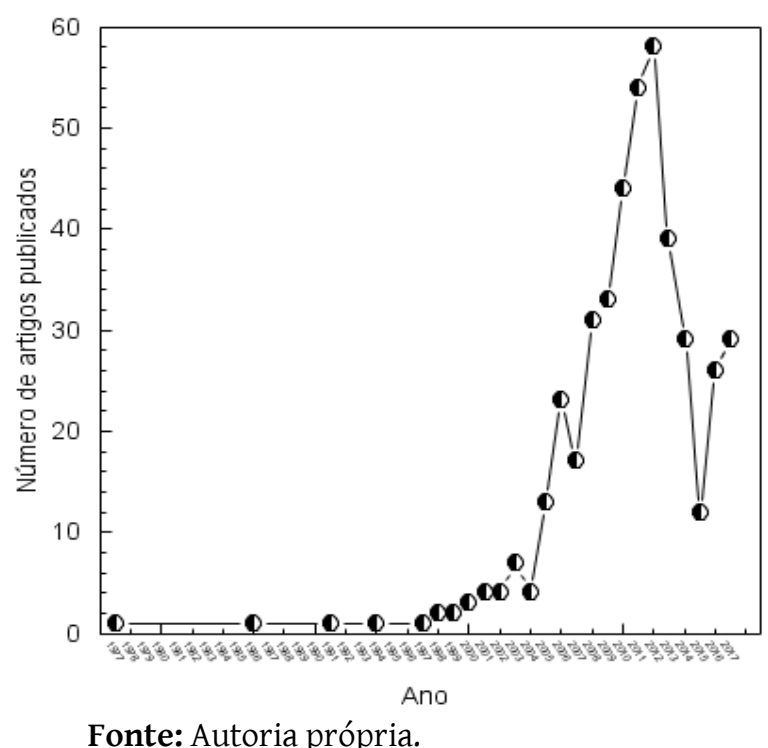

De 1977 a 2004 foram publicados, em média, 2,5 artigos por ano, enquanto que, entre 2005 e 2017, esse número subiu para 31 artigos por ano. Estes resultados evidenciam quatro períodos distintos em relação a publicações de artigos sobre o tema: de 1977 a 2004, onde pouco foi publicado, de 2005 a 2012, com acentuado aumento no número de publicações e, de 2012 a 2015, quando se registrou, em relação ao segundo período, tendência de declínio no número de artigos referentes ao tema. Aqui cabe considerar que no primeiro período, nem 
todas as revisas possuíam acesso eletrônico ou não estavam digitalizadas, o que pode explicar o baixo número de estudos identificados entre 1977 e 2004.

Contudo, no período mais recente, marcado pelos anos de 2016 e 2017, nota-se que o interesse pelo tema voltou a aumentar. Ainda, em relação a esse aumento, no modelo de regressão exponencial ajustado entre anos (variável independente) e número de artigos publicados (variável dependente) obteve-se coeficiente de determinação $\left(\mathrm{R}^{2}=0,84\right)$ e coeficiente positivo $(\beta=0,201)$, indicando que há um aumento do número de artigos publicados por ano no período estudado. No entanto, ao se tomar apenas os dados a partir de 2005 até 2015 , a distribuição é quadrática $\left(R^{2}=0,69\right)$, indicando o aumento no número de artigos até 2012, e um declínio nos três anos subsequentes, voltando a crescer em 2016 e 2017, como já posto.

Os artigos produzidos sobre a temática são de autores de vários países, o que atesta o interesse generalizado sobre o assunto (Figura 3). Os 440 artigos selecionados, provieram de 56 países diferentes, com prevalência de publicações no Brasil (20,2\%), Estados Unidos da América (19,7\%), Colômbia (7,1\%), Espanha (6,6\%), Reino Unido (5,4\%) e México (4,4\%), os demais países somam juntos $36,6 \%$ das publicações.

Figura 3. Distribuição de frequência dos países com maior número de publicações na área de alcoolismo na população universitária.

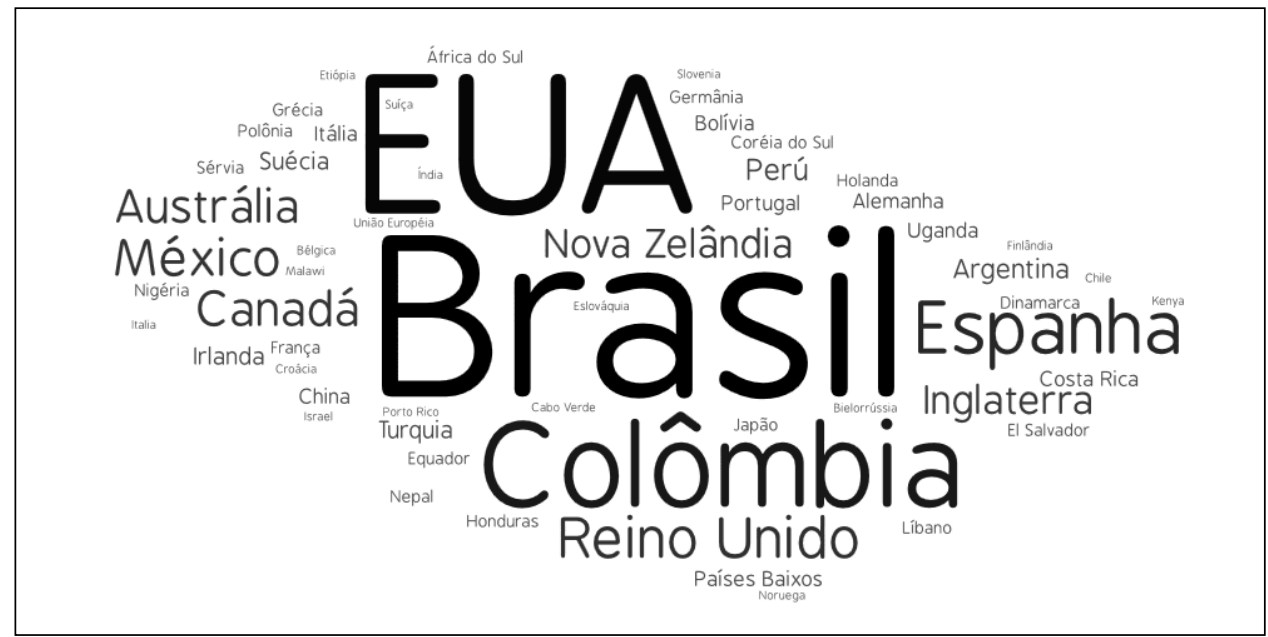

Fonte: Autoria própria.

Dos 440 artigos selecionados, $64,3 \%$ foram publicados em inglês, o que totaliza 283 publicações (figura 4). Essa predominância se deve ao fato de muitos autores publicarem seus artigos neste idioma em revistas de países cuja língua oficial não é o inglês. Dos restantes, 85 
artigos foram publicados em português, representando pouco menos de $20 \%$ e, em menor número, 71 artigos tiveram sua edição em espanhol (16,1\%).

Figura 4. Idiomas utilizados em publicações sobre o tema.

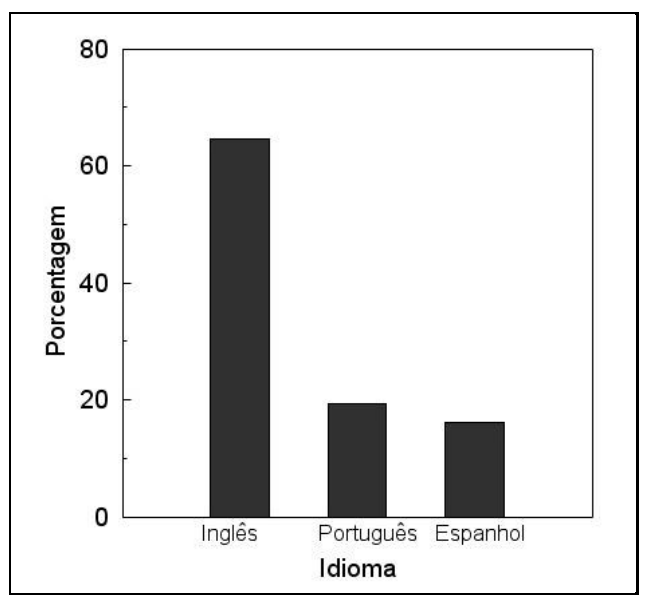

Fonte: Autoria própria.

Nas publicações sobre a temática encontram-se artigos cujo número de autores variam de um a 14, predominando de dois a quatro $(63,8 \%)$, sendo três o número modal, ou seja, aquele com maior número de ocorrência (figura 5).

Figura 5. Número de autores por artigo

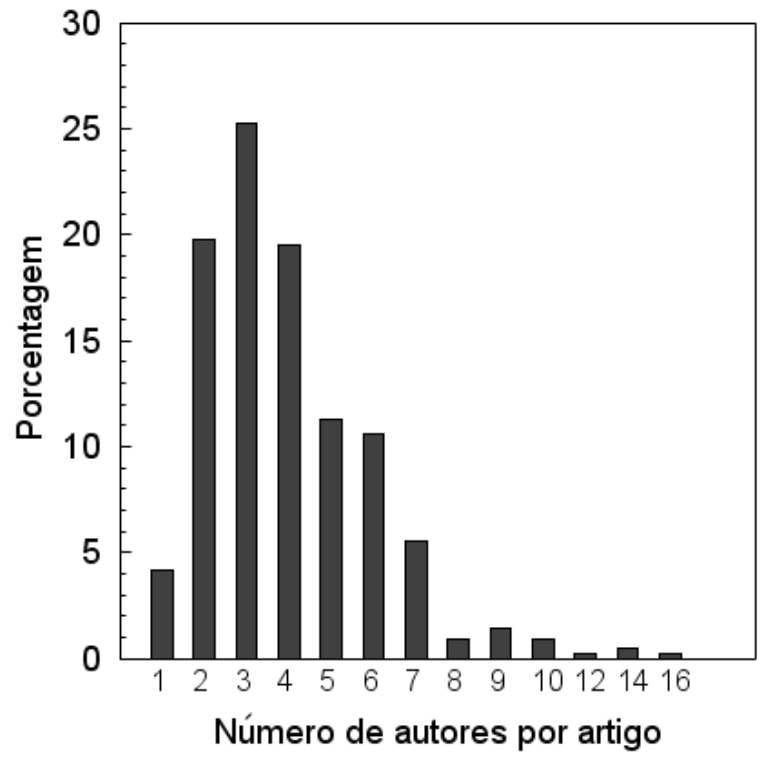

Fonte: Autoria própria. 
Em síntese, os 440 artigos amostrados sobre o alcoolismo universitário não estão concentrados em um ou poucos periódicos somente, revelando uma variedade deles. Quanto ao período de publicação, a partir da análise temporal de 1977 a 2017, observou-se quatro períodos distintos: pequena produção entre 1977 e 2004, acentuado aumento no número de publicações entre 2005 a 2012, com destaque para esse último ano, declínio no período entre 2012 e 2015 e tendência ao aumento das publicações nos dois últimos anos considerados. Quanto à nacionalidade dos autores, pode-se pontuar que são de diversos países, destacandose os brasileiros. No que tange ao idioma de publicação, por sua vez, emerge a língua inglesa. Em relação ao número de autores responsáveis pelo artigo, destaca-se a escrita coletiva (de dois a quatro pessoas).

\section{Caracterísicas metodológicas}

$\mathrm{Na}$ produção dos 440 artigos em foco foram utilizadas diversas abordagens metodológicas (Figura 6), com predominância da quantitativa, em aproximadamente $90 \%$ dos artigos, em relação à qualitativa (5\%), teórica (4\%) e mista (1\%).

Figura 6. Abordagens metodológicas adotados nas publicações

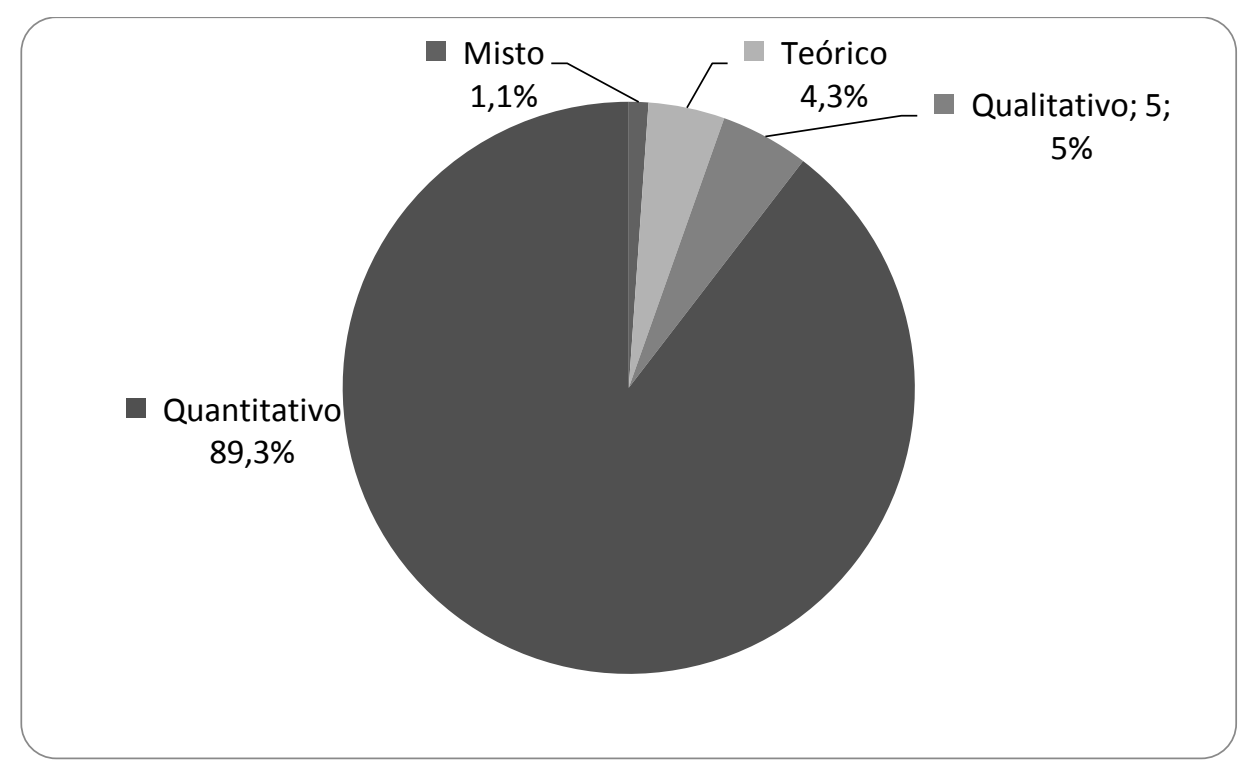

Fonte: Autoria própria. 
Em suma, no que se relaciona às características metodológicas, as publicações revelaram, em sua maioria, abordagens quantitativas. Estas, majoritariamente se deram pela condução de estudos empíricos, ou seja, in loco, revelando realidades, e, ainda, através do uso de escalas validadas, na busca por compreender a relação entre as variáveis em estudo e potenciais explicações e motivações para o consumo de álcool entre univeristários.

\section{Enfoque temático}

Nos 440 artigos analisados foram observadas 1714 palavras-chave diferentes, sendo alcohol a mais citada, seguida dos termos students e college students (tabela 1). Essa ampla distribuição também é representada pela baixa frequência relativa das palavras-chave mais citadas.

Tabela 1 - Frequência das principais palavras-chave das publicações

\begin{tabular}{lcc}
\hline \multicolumn{1}{c}{ Palavras-chave } & $\begin{array}{c}\text { Frequência } \\
\text { absoluta }\end{array}$ & $\begin{array}{c}\text { Frequência } \\
\text { relativa } \\
\text { (\%) }\end{array}$ \\
\hline Alcohol & 112 & 6,5 \\
Students & 73 & 4,3 \\
College students & 53 & 3,1 \\
University students & 52 & 3,0 \\
Alcohol drinking & 42 & 2,5 \\
Alcohol consumption & 32 & 1,9 \\
Alcohol use & 24 & 1,4 \\
Binge drinking & 22 & 1,3 \\
Alcoholism & 21 & 1,2 \\
Street drugs & 17 & 1,0 \\
Other & 1266 & 73,9 \\
\hline
\end{tabular}

Fonte: Autoria própria.

Os resultados evidenciados mostram que há variação entre os temas de estudo (figura 6). Além disso, a quantidade de palavras-chave acompanha o número crescente de publicações no período. Quando considerada a primeira década de estudo, entre 1977 e 1987 
(figura 6a), percebe-se que os temas de interesse das pesquisas centravam-se no consumo e abuso de álcool, associado ao uso de tabaco e cafeína pelos estudantes universitários. No segundo período (1988 a 1998) (figura 6b), observa-se que o consumo de álcool passou a ser associado também ao das drogas ilícitas. Nas duas últimas décadas, período de 1999 a 2017, (figura 6, c e d), os pesquisadores aumentaram os seus escopos de pesquisa e, por consequência, o número de palavras-chave aparece muito superior ao dos anos anteriores.

Compreende-se, na direção desta última tendência, que os estudos têm dado especial atenção aos riscos associados ao consumo e abuso de álcool e outras drogas, com ênfase na saúde dos estudantes universitários. Nesse sentido, convém pontuar a coocorrência de palavras-chave como binge (uso pesado de álcool por tempo determinado, geralmente por mais de um dia), principalmente nos dois últimos períodos (figura 7).

Figura 6. Ocorrências de utilização das palavras-chave das publicações por década.

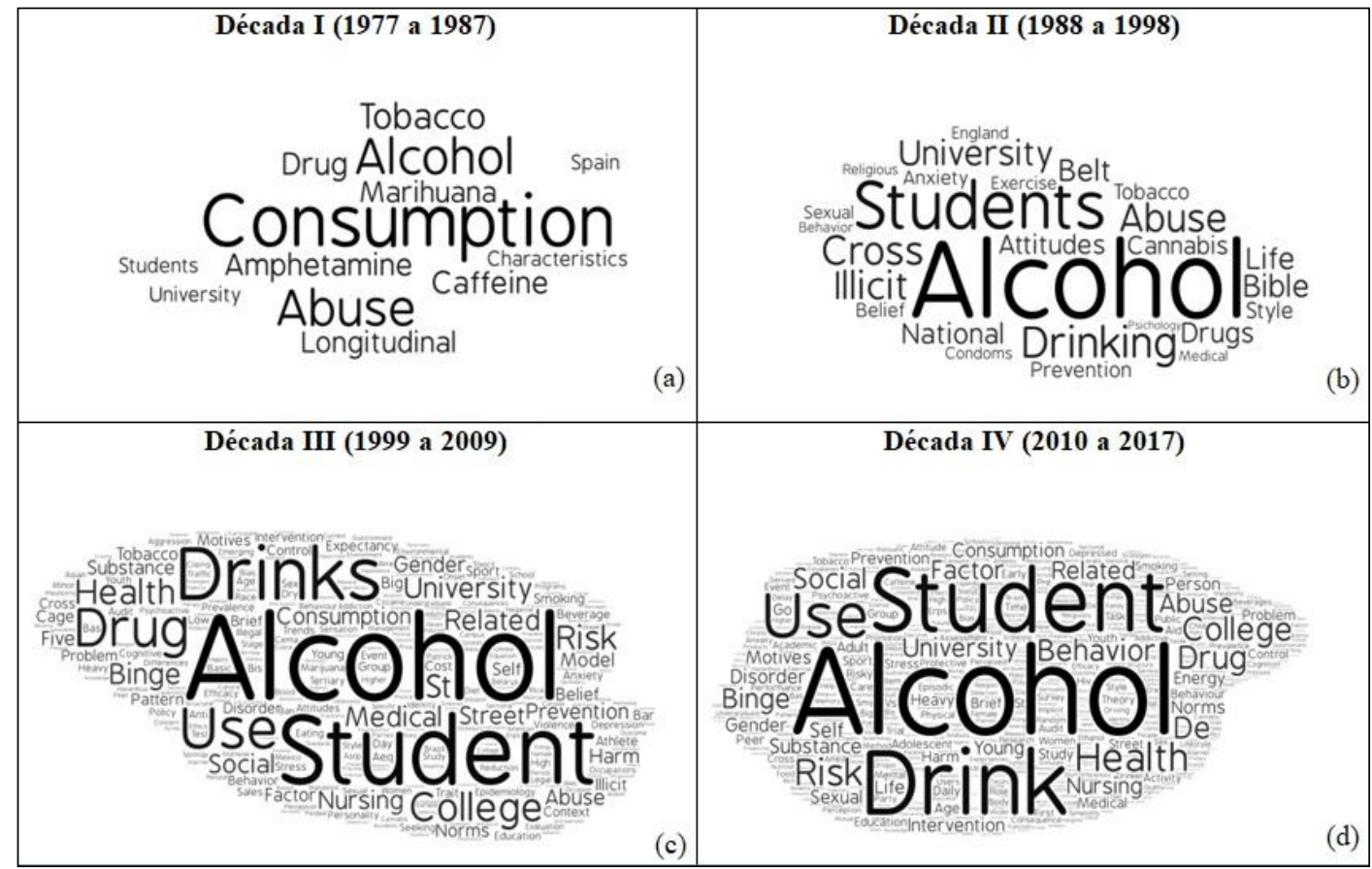

Fonte: Autoria própria.

Quando analisada a conexão entre as palavras-chave por meio da análise de rede, percebe-se que essas são conectadas com os trajetos diretos e indiretos na estrutura geral da rede, sem a ocorrência de fragmentação. Ou seja, sem agrupamentos isolados ou não conectados a outros. Há uma grande quantidade de cliques na rede analisada (154), que são grupos de uma série de palavras-chave com links diretos dentre elas. Observa-se, assim, que 
todos os cliques são compostos por, pelo menos, cinco palavras-chave, que representam as possibilidades de juntarem-se temas e assuntos que permitem entender o consumo de álcool no contexto universitário. Ao reduzir ao mínimo o tamanho do conjunto, observam-se 393 cliques. Portanto, tem-se um grande número de subgrupos que estão reunidos nos conjuntos de três ou cinco palavras-chave, que representam as possibilidades de temas e assuntos comuns.

Em média, a distância geodésica entre duas palavras-chave é de 2,3 graus. Nesse sentido, cada palavra-chave pode ser "alcançada" por meio de 2,3 outras palavras-chave. Em relação à densidade da rede de palavras-chave, que mede a quantidade de ligações que ocorrem entre os nodos que compõem o mesmo ambiente, o indicador possui uma variação entre zero e um. Quanto mais próximo de um, maior é a conectividade existente para a rede (WASSERMAN; FAUST, 1994), ou seja, quanto mais densa se apresentar a rede, mais próxima estará de um. Dessa forma, uma rede poderia ser considerada completa se todos os nós estivessem ligados a outros nós (FERRER, 2010). Neste estudo, foi observada uma baixa densidade $(0,078)$ de rede de palavras-chave, indicando que há $7,8 \%$ do total de ligações possíveis.

A centralização de uma rede é representada pelo grau de vínculos entre atores. Assim, quanto maior a centralização de uma rede, maior é a sua dependência de um número limitado de agentes (WASSERMAN; FAUST, 1994). O grau de centralização da rede de palavras-chave foi $25,95 \%$, o que não indica uma dependência elevada de algumas palavras-chave, mas sim, uma participação de diversas delas na composição da rede. De um modo geral, a média de centralização de todas as palavras-chave foi 0,706 $(\sigma=2.649)$. O grau mínimo de centralização foi de zero, enquanto o máximo verificado foi de 26,51. As cinco palavras-chave mais centrais na rede foram: álcool, estudantes, estudantes universitários e consumo de álcool. Ou seja, o tema consumo de álcool por estudantes universitários é identificado na literatura principalmente por essas palavras-chave mais centrais na rede.

A representação gráfica apresentada à Figura 8 sintetisa a distribuição das palavraschave e o grau de centralização na rede. Especificamente, quanto mais central é a palavrachave, maior é o grau de centralização e, por conseguinte, maior é a importância de ligação à rede. 
Figura 8. Rede de palavras-chave organizada pelo grau de centralização dos estudos.

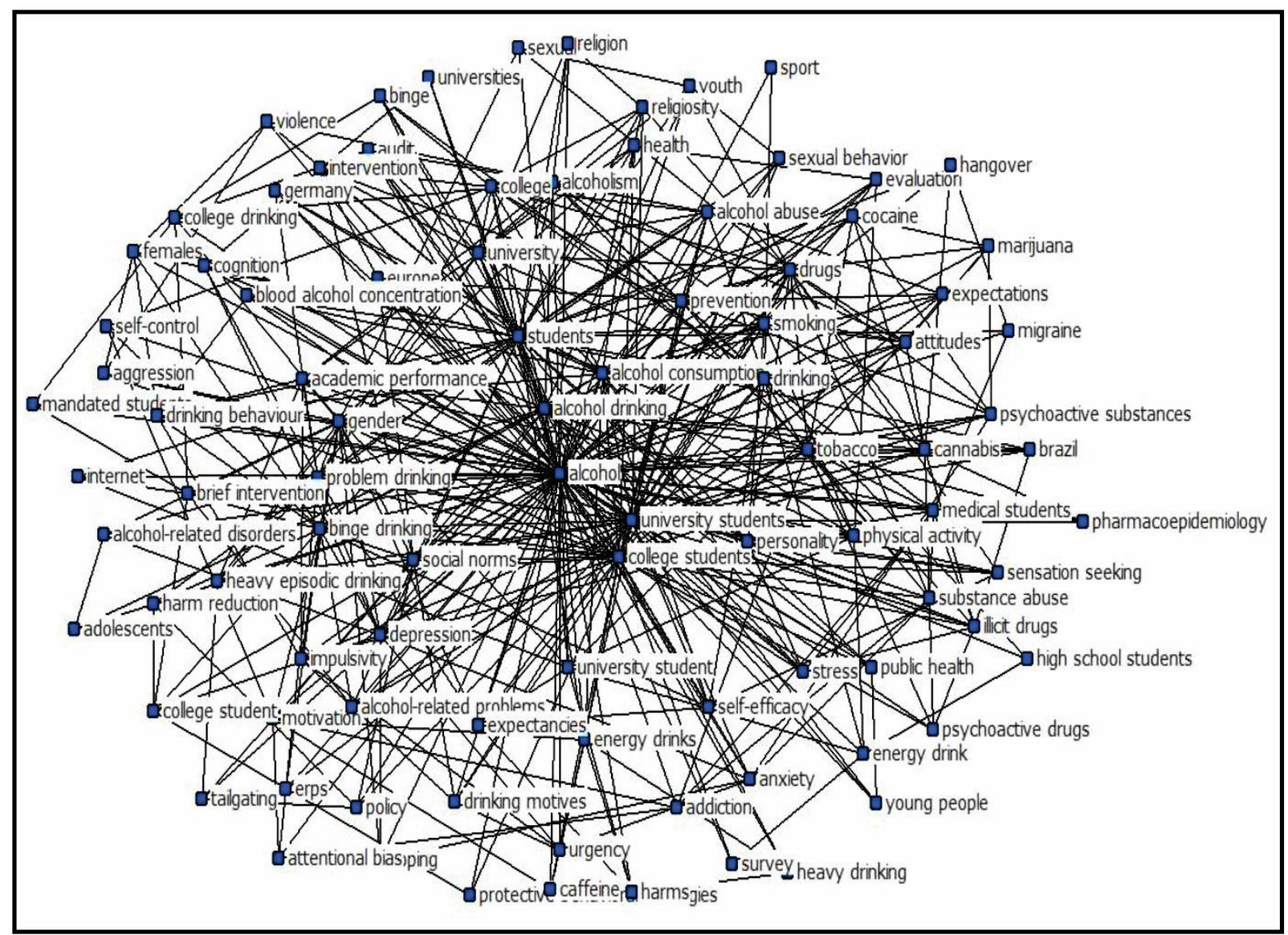

Fonte: Autoria própria.

Na rede de palavras-chave analisadas, pode-se verificar que o grau de proximidade é de $47,79 \%$ (figura 8), o que indica que a rede cria um nível elevado de proximidade entre as palavras-chave. Especificamente, a rede apresenta média de $43,43(\sigma=5,21)$ de proximidade entre os nós, em uma gama de 31,93 a 67,13 de proximidade. As palavras-chave mais próximas foram álcool, estudantes, estudantes universitários e consumo do álcool. Importante notar que tais palavras assim como são as mais próximas, também foram identificadas anteriormente como as mais centrais na rede. Assim, considerando-se as questões de centralidade, realizou-se a análise de subgrupo com fundamento baseado em blocos, para medir a ligação ou relação entre as principais palavras-chave na rede, buscando-se a melhor compreensão do enfoque temático dos estudos. Tal análise possibilitou identificar que o núcleo da rede é formado por 13 palavras-chave, identificadas pela Figura 9. Por meio destas percebe-se que os 440 artigos buscaram investigar o consumo de álcool entre universitários relacionando-o aos fatores de risco, às drogas de rua e aos distúrbios relacionados às substâncias. 
Figura 9 - Bloco central na rede de palavras chave dos estudos

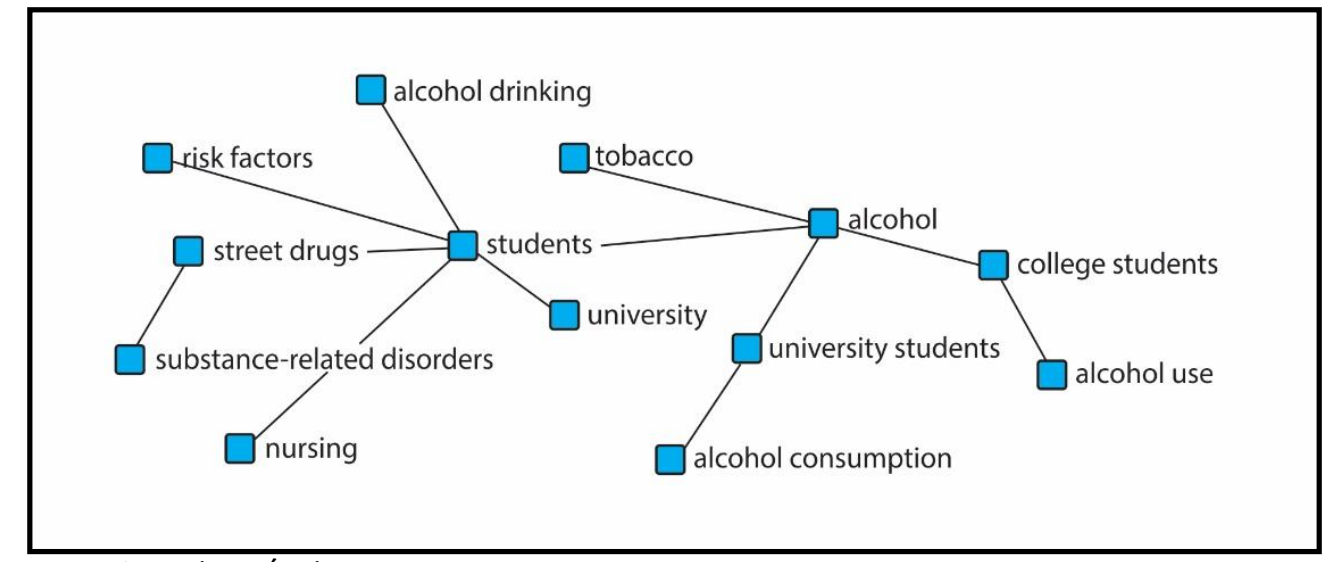

Fonte: Autoria própria.

Em síntese, a análise temática evidenciou que embora tenha ocorrido uma evolução na quantidade de artigos publicados sobre o tema no período analisado, as palavras-chave utilizadas têm se mantido semelhantes. Importante destacar que a partir dos anos 2000, além das palavras consumo de álcool e estudantes universitários, os estudos começam a diversificar as abordagens e a ampliar o sentido destas, evidenciando maior amplitude dos estudos. Esse direcionamento é percebido no uso de palavras-chave como estudantes, em detrimento de estudantes universitários.

Ainda, em termos de conclusão deste capítulo, pontua-se que a conexão entre as palavras na rede é de cerca de 2,3 palavras, enquanto que a densidade de palavras-chaves foi considerada baixa $(7,8 \%)$. As palavras mais centrais e que direcionam a grande maioria dos estudos foram: álcool, estudantes, estudantes universitários e consumo de álcool. Aliado a isso, também convém destacar elevada proximidade (47,79\%) entre todas as palavras-chave da rede. Esses achados, em conjunto, denotam que o campo tem alcançado uma homogeniedade em torno dos assuntos estudados e não tem evidenciado a ocorrência de temas correlatos ou novas abordagens. Isso, em função de que não são apresentadas distâncias ou graus de proximidade entre as palavras-chave que evidenciem essa ocorrência.

\section{DISCUSSÃO}

Os resultados do estudo, revelados pela análise bibliométrica de 440 artigos internacionais publicados entre os anos de 1977 e 2017, mostram que o consumo de álcool 
dentre universitários tem sido tema de grande interesse entre a comunidade científica mundial, especialmente nos países do continente americano. Pesquisadores vinculados a instituições brasileiras e estadunidenses são os principais autores de artigos sobre o tema. Isto pode indicar que o fenômeno é mais latente nesses dois países, em comparação a outros, e reflete necessidade premente de buscar soluções ao problema de consumo de álcool dentre estudantes (MANN; SMITH; KRISTJANSSON, 2016; MOLA et al., 2017a).

Observou-se, também, que embora a presença de autores brasileiros e de outros países latino americanos seja elevada, a grande maioria dos artigos foi publicada em língua inglesa. Esta preferência pode indicar a busca por uma audiência maior e, consequentemente, um mais expressivo impacto para o artigo.

Além disso, o elevado número de periódicos que publicaram artigos sobre o tema (172) no período considerado neste estudo (1977 a 2017), reforça a importância que a comunidade científica atribui ao assunto. Esses dados revelam a preocupação de pesquisadores de diferentes áreas com o crescente consumo de álcool, que se inicia cada vez mais precocemente, principalmente entre o público universitário (MIRI et al., 2011; ROGOWSKA, 2014). A análise numérica das publicações ao longo dos anos de 1977 a 2017 sinaliza tendência positiva de crescimento de artigos sobre alcoolismo, com a retomada no interesse pela temática nos últimos dois anos do período estudado (2015 a 2017).

Com referência aos temas abordados nas publicações em estudo, constata-se grande diversidade de palavras-chave. As expressões alcohol, college students e university students foram as que remeteram a um número maior de artigos dedicados ao estudo do problema de consumo de álcool entre menores de 18 anos (JONES; GORDON, 2017) e maiores de 18 anos (KRAČMAROVÁ et al., 2011), respectivamente. A alta dispersão das palavras-chave é comprovada pela baixa densidade da rede formada por elas $(7,8 \%)$.

Além disso, a análise de centralidade evidencia a associação entre os estudos sobre álcool e estudantes, uma vez que ambas as palavras estão dentre as mais centrais na rede de palavras-chave. A concentração nessas palavras, associada ao forte grau de proximidade entre elas na rede, pode ser uma indicação de que os pesquisadores têm se dedicado a estudos envolvendo tópicos correlatos, sem aumento da abrangência de novos horizontes de pesquisa. No bloco central da rede evidencia-se que a dispersão e o aprofundamento em 
outros assuntos não são elevados e, quando ocorre, envolve estudos sobre comportamentos de risco, drogas, tabaco e enfermagem.

Neste direcionamento, as pesquisas sobre a temática serem realizadas em torno de temas correlatos, pode decorrer do fato de que, apesar de os estudos levantarem a questão do alccolismo entre universitário há, pelo menos quatro décadas, e apontarem eventuais soluções, poucas ações concretas tem sido efetivadas para resolver a questão, ou mesmo que os estudos científicos sobre o tema tem sido negligenciados pelos tomadores de decisão e formuladores de políticas de saúde.

É possível perceber, portanto, que essas associações revelam dois grandes enfoques da pesquisa sobre alcoolismo. O primeiro buscando compreender elementos que levem à eliminação de um comportamento nocivo entre menores de idade (JIMÉNEZ-MEJÍAS et al., 2015; MOURE-RODRÍGUEZ et al., 2016; MOLA et al., 2017b). O segundo, por sua vez, procurando entender tanto as consequências deste comportamento entre estudantes (MOURERODRÍGUEZ et al., 2014) quanto os elementos que influenciam na redução do consumo de álcool (RUISOTO et al., 2016; MORIOKA et al., 2017).

A opção metodológica mais adotada pelos autores dos trabalhos analisados é a abordagem quantitativa, seguramente, por ser a que permite realizar uma série de procedimentos estatísticos, como obter correlações, determinar padrões, bem como abranger um número maior de sujeitos pesquisados. Os resultados indicam que essa abordagem tem sido adequada nas investigações acerca do uso de álcool, uma vez que as pesquisas buscam estimativas de hábitos de consumo (MANN; SMITH; KRISTJANSSON, 2016; JONES; GORDON, 2017), possíveis fatores causais (JOHNSON et al., 2016b; DE LOOZE et al., 2017), comparações (RUISOTO et al., 2016; TEIXIDÓ-COMPANÓ et al., 2016) e associações com outras variáveis (MOURE-RODRÍGUEZ et al., 2014).

Especificando-se tal recorte metodológico, a maior parte dos estudos utiliza o método empírico. Este, provavelmente por permitir que as associações causais entre os antecedentes e consequentes do consumo de álcool sejam testadas em convergência com medidas atitudinais ou comportamentais. Como exemplo das variáveis antecedentes pode-se citar causas individuais (ALVEAR-GALINDO et al., 2015; RUISOTO et al., 2016; JONES; GORDON, 2017), da família (ALVEAR-GALINDO et al., 2015; DE LOOZE et al., 2017; JONES; GORDON, 2017; EILER 
et al., 2018) e do contexto escolar. Ainda, do grupo de pares (JONES; GORDON, 2017), do trabalho (TEIXIDÓ-COMPANÓ et al., 2016), da mídia (MORIOKA et al., 2017) e o acesso facilitado a bebidas pelos jovens (JOHNSON et al., 2016a, 2016b; MANN; SMITH; KRISTJANSSON, 2016).

No que se refere às variáveis consequentes, tem-se associação com a imprudência no trânsito (JIMÉNEZ-MEJÍAS et al., 2015; REZAEE-ZAVAREH et al., 2017), as relações sexuais de risco (MOURE-RODRÍGUEZ et al., 2016; MOLA et al., 2017a), ao uso de cigarro e outras drogas (KRAČMAROVÁ et al., 2011) e, ainda, às doenças oriundas do excesso de consumo de álcool (MOURE-RODRÍGUEZ et al., 2014; ALVEAR-GALINDO et al., 2015; AL MAKADMA, 2017). Assim, diante de tais dados, é possível dizer que os estudos buscaram testar eventuais mecanismos que possam influenciar, positivamente ou negativamente, o consumo ou a intenção de uso de álcool por estudantes de nível superior, e suas potenciais consequências.

\section{CONCLUSÃO}

A transição da adolescência para a vida adulta é marcada por significativas mudanças na vida dos jovens, dentre estas, as possibilitadas pelo ingresso no ensino superior. Diversas pesquisas mostraram que, nesse período, o aumento nos padrões de consumo de álcool tem sido problema recorrente e observado em âmbito mundial, uma vez que o excesso, além de sérios danos à saúde, pode tornar o indivíduo suscetível a outros comportamentos de risco. Por isso, buscou-se, por meio de um estudo bibliométrico, analisar as ênfases atribuídas pelos autores em artigos científicos internacionais, aos fatores associados ao consumo de bebidas alcoólicas por estudantes universitários, considerando o período temporal de 1977 a 2017.

A partir das análises realizadas, possibilitadas pela observância de 440 artigos, constatou-se a predominância de estudos empíricos com viés quantitativo. Esses demonstram a preocupação dos pesquisadores em testar o consumo de álcool e sua relação com outras variáveis, na busca pela compreensão dos hábitos de consumo, fatores causais e consequências dessa prática. Além disso, pode-se observar que a pesquisa nessa área é crescente, tendo o continente americano como o mais preocupado com os estudos sobre a temática, o que evidencia a inquietação dessa região com os jovens que consomem álcool, sobremaneira, os que estão cursando estudos em nível superior. 
Tal preocupação ancora-se, especialmente, nas consequências que esse comportamento acarreta. E por assim ser, revela a necessidade de intervenções mais precoces com estudantes universitários, como o desenvolvimento de programas de prevenção adequados nas universidades. Isso, devido ao fato de perceber-se nos constructos analisados que é realidade o consumo de álcool nesse contexto, assim como a grande quantidade e o início cada vez mais precoce do hábito.

Diante de tais constatações, este estudo não pretendeu esgotar a literatura sobre o consumo de álcool entre os universitários, mas trazer um panorama das pesquisas mundiais. Salienta-se, nessa direção, que o cenário aqui traçado permitiu a realização de um primeiro mapeamento da produção científica/acadêmica sobre o consumo de álcool entre os estudantes universitários. Os dados aqui expostos sintetizam as discussões sobre o tema ao longo do período de 1977 a 2017 e conduzem a uma reflexão e a proposições sobre novas formas e arranjos de pesquisa.

Percebe-se, dessa forma, a oportunidade e a necessidade de se desenvolver pesquisas em diferentes áreas do conhecimento, visando compreender os comportamentos, as consequências do consumo, as normas sociais e as políticas públicas e organizacionais voltadas para a redução do consumo de álcool entre o público universitário. Foi um achado deste estudo, que os pesquisadores têm se dedicado a pesquisas envolvendo praticamente sempre os mesmos tópicos correlatos, sem aumento da abrangência de novos horizontes. Do mesmo modo, observou-se que não existem periódicos especializados no assunto e há escassez do delineamento qualitativo de pesquisas, o que põe claro que investimentos em novos e mais abrangentes estudos devem acontecer.

Outros estudos bibliométricos podem ser realizados protagonizando-se estudos específicos dos países que mais publicaram sobre o tema. Isso, com o objetivo de compreender os avanços produzidos pelas pesquisas e verificando-se a evolução dos padrões de consumo entre os universitários, bem como relacionando-se o consumo aos contextos socioculturais em diferentes épocas.

Como limitação do estudo salienta-se que, por tratar-se de revisão bibliográfica, considerou-se um recorte das pesquisas publicadas nas revistas internacionais de um período 
específico (1977 a 2017). Portanto, os resultados dizem respeito apenas a esse universo pesquisado, não podendo ser generalizados.

\section{REFERÊNCIAS}

AL MAKADMA, A. S. Adolescent health and health care in the Arab Gulf countries: Today's needs and tomorrow's challenges. International Journal of Pediatrics and Adolescent Medicine, v. 4, n. 1, p. 1-8, 2017. Disponível em

https://reader.elsevier.com/reader/sd/pii/S235264671730008X?token=B9CB515262D3BBA86DC7342264ACF7B C2B21B2C22301802796BB713886859AE73385C27D4B6FD9753D5E6F37DCEBB251\&originRegion=us-east-

1\&originCreation $=20210430131926$

ALVEAR-GALINDO, M. G.; YAMAMOTO-KIMURA, L. T.; C. MORÁN-ÁLVAREZ, C.; RODRÍGUEZ-PÉREZ, A.; SOLÍSTORRES, C.; VARELA-MEJÍA, H. F.; FAJARDO-YAMAMOTO, M. et al. Tobacco use , alcohol consumption and family history, such as risk of chronic disorders in university students. Revista Médica del Hospital General de

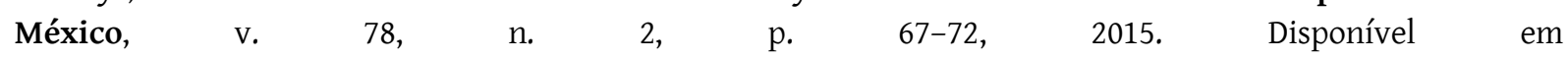
https://www.sciencedirect.com/science/article/pii/S0185106315000256

American Psychiatric Association - APA. Diagnostic and Statistical Manual of Mental Disorders (DSM-IV). 4.ed. Washington: American Psychiatric Association, 1994.

BEDENDO, A.; ANDRADE, A. L. M.; NOTO, A. R. Intervenções via Internet para redução do consumo de álcool entre universitários: uma revisão sistemática. Revista Panamericana de Salud Pública, v. 42, p. 1-10, 2018. Disponível

em

https://iris.paho.org/bitstream/handle/10665.2/49118/v42e542018.pdf?sequence=1\&isAllowed=y

DE LOOZE, M. E.; DORSSELAERB, S. A. F. M.; MONSHOUWERB, K. VOLLEBERGHET, A. M. V. Trends in adolescent alcohol use in the Netherlands, 1992-2015: Differences across sociodemographic groups and links with strict parental rule-setting. International Journal of Drug Policy, v. 50, p. 90-101, 2017. Disponível em https://www.researchgate.net/publication/320702922_Trends_in_adolescent_alcohol_use_in_the_Netherlan ds_1992-2015_Differences_across_sociodemographic_groups_and_links_with_strict_parental_rule-setting

EILER, W. J. A.; DZEMIDZICA, M.; SOEURTA, C. M.; CARRONA, C. R.; OBERLINA, B. G.; CONSIDINEC, R. V.; HAREZLAKD, J.; KAREKENET, D. A. Family history of alcoholism and the human brain response to oral sucrose. NeuroImage: Clinical, v. 17, p. 1036-1046, 2018. Disponível em https://www.researchgate.net/publication/321772771_Family_history_of_alcoholism_and_the_human_brain response_to_oral_sucrose

FARIA, R.; VENDRAME, A.; SILVA, R.; PINSKY, I. Propaganda de álcool e associação ao consumo de cerveja por adolescentes. Revista de Saúde Pública, v. 45, p. 441-447, 2010. Disponível em https://www.scielo.br/pdf/rsp/v45n3/1827.pdf

FERREIRA, A. P. S. O consumo de álcool e comportamentos de risco nos estudantes do ensino superior. [s.l.] Universidade de Aveiro, 2008. Disponível em https://ria.ua.pt/bitstream/10773/1015/1/2008001354.pdf

FERRER, M. L. Comparación en las estructuras de colaboración y pautas de citación entre áreas científicas a través del ARS. Redes. Revista hispana para el análisis de redes sociales, v. 19, n. 03, p. 39-63, 2010. Disponível em https://www.raco.cat/index.php/Redes/article/view/217078/293455 
FILHO, V. C. B.; CAMPOS, W. DE.; LOPES, A. DA S. Prevalence of alcohol and tobacco use among Brazilian adolescents: a systematic review. Revista de Saúde Pública, v. 46, n. 5, p. 901-917, 2012. Disponível em https://www.scielo.br/scielo.php?script=sci_arttext\&pid=S0034-89102012000500018

JAVIER, S. J.; BELGRAVE, F. Z.; HILL, K. E. V.; RICHARDSON, J. T. Ethnic and gender differences in normative perceptions of substance use and actual use among college students. Journal of Ethnicity in Substance Abuse, $\begin{array}{llllllll}\text { v. } & 12, & \text { n. } & 3, & \text { p. 228-241, } & 2013 . & \text { Disponível } & \text { em }\end{array}$ https://www.tandfonline.com/doi/abs/10.1080/15332640.2013.798847

JIMÉNEZ-MEJÍAS, E.; MEDINA-GARCÍA, M. A.; MARTÍNEZ-RUIZ, V.; PULIDO-MANZANERO, J.; FERNÁNDEZVILLA, T.; GRUPO UNIHCOS. Consumo de drogas e implicación en estilos de conducción de riesgo en una muestra de estudiantes universitarios. Proyecto uniHcos. Gaceta Sanitaria, v. 29, p. 4-9, 2015. Disponível em https://www.sciencedirect.com/science/article/pii/S0213911115000758

JOHNSON, S. J.; ALFORD, C.; STEWART, K.; VERSTER, J. C. A UK student survey investigating the effects of consuming alcohol mixed with energy drinks on overall alcohol consumption and alcohol-related negative consequences. Preventive Medicine Reports, v. 4, p. 496-501, 2016a. Disponível em https://www.sciencedirect.com/science/article/pii/s2211335516301115

JOHNSON, S. J.; ALFORD, C.; VERSTER, J. C.; STEWART, K. Motives for mixing alcohol with energy drinks and other non-alcoholic beverages and its effects on overall alcohol consumption among UK students. Appetite, v. 96, p. 588-597, jan. 2016b. Disponível em https://pubmed.ncbi.nlm.nih.gov/26463015/

JONES, S. C.; GORDON, C. S. A systematic review of children's alcohol-related knowledge, attitudes and expectancies. Preventive Medicine, v. 105, p. 19-31, 2017. Disponível em https://www.sciencedirect.com/science/article/pii/S0091743517302918

KRAČMAROVÁ, L.; PETRELLI, F.; GRAPPASONNI, I. Tobacco, alcohol and illegal substances : experiences and attitudes among Italian university students. Revista da Associação Médica Brasileira, v. 57, n. 5, p. 513-518, 2011. Disponível em $\quad$ https://www.scielo.br/scielo.php?script=sci_abstract\&pid=S0104$\underline{42302011000500009 \& \operatorname{lng}=\text { en\&nrm=iso }}$

LARANJEIRA, R. II Levantamento Nacional de álcool e drogas: o uso de cocaína e crack no Brasil. São Paulo: Unifesp, Inpad/Uniad, 2012. Disponível em https://inpad.org.br/wp-content/uploads/2014/03/Lenad-IIRelat\%C3\%B3rio.pdf

LORANT, V.; NICAISE, P.; SOTO, V. E.; D'HOORE, W. Alcohol drinking among college students: College responsibility for personal troubles. BMC Public Health, v. 13, n. 615, p. 1-9, 2013. Disponível em https://bmcpublichealth.biomedcentral.com/articles/10.1186/1471-2458-13-615

MALTA, D. C.; MASCARENHAS, M. D. M.; PORTO, D. L.; BARRETO, S. M.; MORAIS NETO, O. L. D. Exposição ao álcool entre escolares e fatores associados. Rev Saúde Pública, v. 48, n. 1, p. 52-62, 2014. Disponível em https://www.scielo.br/scielo.php?script=sci_arttext\&pid=S0034-89102014000100052

MANN, M. J.; SMITH, M. L. S.; KRISTJANSSON, A. L. Energy drink consumption and substance use risk in middle school students. Preventive Medicine Reports, v. 3, p. 279-282, 2016. Disponível em https://pubmed.ncbi.nlm.nih.gov/27419027/

MCCAMBRIDGE, J.; MCALANEY, J.; ROWE, R. Adult consequences of late adolescent alcohol consumption: a systematic review of cohort studies. PLoS Medicine, v. 8, n. 2, p. e1000413. 2011. Disponível em https://pubmed.ncbi.nlm.nih.gov/21346802/ 
MIRI, M.; BAHRAMI, H.; SHAHYAD, S.; ASADI, M.; SHIRALIPOUR, A.; BARGHI, I.; MOHAMADPUR, H. Prediction of alcohol oriented perceived educational styles. Procedia - Social and Behavioral Sciences, v. 15, p. 904-907, 2011. Disponível em https://www.researchgate.net/publication/251713300_Prediction_of_Alcohol_oriented_Perceived_Education al_Styles

MOHER, D.; LIBERATI, A.; TETZLAFF, J.; ALTMAN, D. G.; PRISMA GROUP. Preferred Reporting Items for Systematic Reviews and Meta-Analyses: The PRISMA Statement (Reprinted from Annals of Internal Medicine). Physical Therapy, v. 89, n. 9, p. 873-880, 2009. Disponível em https://pubmed.ncbi.nlm.nih.gov/19622511/

MOLA, R.; ARAÚJO, R. C.; OLIVEIRA, J. V. B.; CUNHA, S. B.; SOUZA, G. F. F.; RIBEIRO, L. P.; PITANGUI, A. C. Association between the number of sexual partners and alcohol consumption among schoolchildren. Jornal de Pediatria, v. 93, n. 2, p. 192-199, 2017. Disponível em https://www.scielo.br/pdf/jped/v93n2/pt_0021-7557jped-93-02-0192.pdf

MORIOKA, H.; ITANI, O.; OSAKI, Y.; HIGUCHI, S.; JIKE, M.; KANEITA, Y.; KANDA, H.; NAKAGOME, S.; OHIDA, T. The association between alcohol use and problematic internet use: A large-scale nationwide cross-sectional study of adolescents in Japan. Journal of Epidemiology, v. 27, n. 3, p. 107-111, mar. 2017. Disponível em https://www.sciencedirect.com/science/article/pii/S091750401630123X

MOURE-RODRÍGUEZ, L; JUAN-SALVADORES, P.; CAAMANO-ISORNA, F. Heavy drinking and alcohol-related injuries in college students. Gaceta Sanitaria, v. 28, n. 5, p. 376-380, 2014. Disponível em https://www.researchgate.net/publication/261607133_Heavy_drinking_and_alcohol-

$\underline{\text { related_injuries_in_college_students }}$

MOURE-RODRÍGUEZ, L.; DOALLO, S.; JUAN-SALVADORES, P.; CORRAL, M.; CADAVEIRA, F.; CAAMANO-ISORNA, F. Consumo intensivo de alcohol y cannabis, y prácticas sexuales de riesgo en estudiantes universitarios. Gaceta Sanitaria, v. $30, \quad$ n. 6, p. 438-443, 2016. Disponível em https://www.sciencedirect.com/science/article/pii/s0213911116300358

ORGANIZAÇÃO MUNDIAL DA SAÚDE - O. M. S. Self-help strategies for cutting down or stopping substance use: a guide. (WHO Press, Ed.) Geneva, Switzerland: World Health Organization, 2010. Disponível em https://www.who.int/substance_abuse/publications/assist_self_help/en/

ORGANIZAÇÃO MUNDIAL DA SAÚDE - O. M. S. World health statistics 2017: monitoring health for the SDGs, Sustainable Development Goals. Geneva, Switzerland: 2017. Disponível em https://apps.who.int/iris/handle/10665/255336

PARÉ, G.; TRUDEL, M.; JAANA, M.; KITSIOU, S. Synthesizing information systems knowledge: A typology of literature reviews. Information and Management, v. 52, n. 2, p. 183-199, 2015. Disponível em https://edisciplinas.usp.br/pluginfile.php/4150288/mod_resource/content/1/2.4.Pare\%20et\%20al.\%202015\%2 0-\%20literature\%20review.pdf

PILLON, S. C.; SANTOS, M. A. D.; GONÇALVES, A. M. D. S.; ARAÚJO, K. M. D. Uso de álcool e espiritualidade entre estudantes de enfermagem. Revista da Escola de Enfermagem da USP, v. 45, n. 1, p. 100-107, 2011. Disponível em https://www.scielo.br/pdf/reeusp/v45n1/14.pdf

RABELO, M. O.; PRATES, T. E. C.; SAMPAIO, C. A. Consumo de álcool por estudantes da área da saúde: uma Revisão Sistemática da Literatura. Revista Brasileira de Pesquisa em Ciências da Saúde, v. 4, n. 1, p. 01-08, 2017. Disponível em http://revistas.icesp.br/index.php/RBPeCS/article/view/99

REZAEE-ZAVAREH, M. S.; SALAMATI, P.; RAMEZANI-BINABAJ, M.; SAEIDNEJAD, M. Alcohol consumption for simulated driving performance: A systematic review. Chinese Journal of Traumatology - English Edition, v.

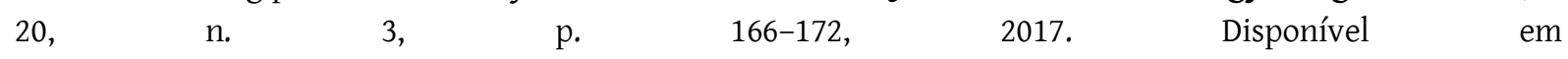


https://www.researchgate.net/publication/316145667_Alcohol_consumption_for_simulated_driving_perfor mance_A_systematic_review

RINKER, D. V.; NEIGHBORS, C. Social influence on temptation: Perceived descriptive norms, temptation and restraint, and problem drinking among college students. Addictive Behaviors, v. 38, n. 12, p. 2918-2923, 2013. Disponível em https://www.ncbi.nlm.nih.gov/pmc/articles/PMC3980677/

ROGOWSKA, A. M. Association between Type A/B Behavior Pattern and Alcohol Consumption in Undergraduate Students. Procedia - Social and Behavioral Sciences, v. 159, p. 682-685, 2014. Disponível em https://www.sciencedirect.com/science/article/pii/S1877042814065987

ROMANO, M.; DUAILIBI, S.; PINSKY, I.; LARANJEIRA, R. Pesquisa de compra de bebidas alcoólicas por adolescentes em duas cidades do Estado de São Paulo. Rev. Saúde Pública, v. 41, n. 4, p. 495-501, 2007. Disponível em https://www.scielo.br/pdf/rsp/v41n4/5621.pdf

RUISOTO, P.; CACHO, R.; LÓPEZ-GOÑI, J. J.; VACA, S.; JIMÉNEZ, M. Prevalencia y perfil de consumo de alcohol en estudiantes universitarios en Ecuador. Gaceta Sanitaria, v. 30, n. 5, p. 370-374, 2016. Disponível em https://www.scielosp.org/article/gs/2016.v30n5/370-374/

SALLES, T. A.; CHAVES, E. C. L.; MOREIRA, D. S.; BRITO, M. V. N.; MENDONÇA, H. M. .C. R.; OLIVEIRA, K. Estratégias de prevenção ou redução do consumo de drogas para adolescentes: revisão sistemática da literatura. Revista Eletrônica de Enfermagem, v. 18, p. 1-14, 2016. Disponível em https://revistas.ufg.br/fen/article/view/36796

SANTOS, M. C. F.; PEREIRA, D. S.; SIQUEIRA, M. M. Uso de álcool e tabaco entre estudantes de psicologia da Universidade Federal do Espírito Santo. Jornal Brasileiro de Psiquiatria, v. 62, n. 1, p. 22-30, 2013. Disponível em https://www.scielo.br/scielo.php?pid=S0047-20852013000100004\&script=sci_abstract\&tlng=pt

SILVA, D. A. S.; PETROSKI, E. L. The simultaneous presence of health risk behaviors in freshman college students in Brasil. Journal of Community Health, v. 37, n. 3, p. 591-598, 2012. Disponível em https://link.springer.com/article/10.1007/s10900-011-9489-9

SILVA, L. V.; MALBERGIER, A.; STEMPLIUK, V. D. A.; ANDRADE, A. G. D. Fatores associados ao consumo de álcool e drogas entre estudantes universitários. Revista de Saúde Pública, v. 40, n. 2, p. 280-288, 2006. Disponível em https://www.scielo.br/scielo.php?script=sci_arttext\&pid=S0034-89102006000200014

TEIXIDÓ-COMPANÓ, E. et al. Differences between men and women in substance use: The role of educational level and employment status. Gaceta Sanitaria, v. 32, n. 1, p. 41-47, 2016. Disponível em https://www.sciencedirect.com/science/article/pii/S0213911117300572

WASSERMAN, S.; FAUST, K. Social Network Analysis: Methods and Applications. [s.l.] Cambridge University Press, 1994.

ZAPPE, J. G.; ALVES, C. F.; DELL'AGLIO, D. D. Comportamentos de risco na adolescência: Revisão sistemática de estudos empíricos. Psicologia em Revista, v. 24, n. 1, p. 79-100, 2018. Disponível em http://pepsic.bvsalud.org/scielo.php?script=sci_abstract\&pid=S1677-11682018000100006.

\section{(c)) EY}

Este trabalho está licenciado com uma Licença Creative Commons - Atribuição 4.0 Internacional. 